\title{
DIMETHYL SULPHATE POISONING
}

\author{
BY \\ T. R. LITTLER and R. B, McCONNELL \\ From the Medical Unit, David Lewis Northern Hospital, Liverpool
}

(RECEIVED FOR PUBLICATION SEPTEMBER 18, 1954)

Dimethyl sulphate $\left(\left(\mathrm{CH}_{3}\right)_{2} \mathrm{SO}_{4}\right)$ has been used since the beginning of the century as a methylating agent in the preparation of organic chemical products and colouring agents, in the perfume industry, and in other processes. It is a colourless or yellowish liquid of oily consistency which vaporizes at $50^{\circ} \mathrm{C}$. and has a slight piquant smell. Both the liquid and the vapour are vesicants and by virtue of this property may be used in warfare.

Following exposure there is an intense local action on the skin and mucous membranes. The skin changes vary from a simple redness to vesication according to the length of contact. Genital and mucous membrane lesions, which are due to the vapour only in most cases, may be delayed for some hours. Changes in the eyes consist of conjunctivitis, oedema of the lids, photophobia, lacrimation, and, in severe cases, keratitis. In the upper respiratory tract oedema or even ulceration of the lips and pharynx are prominent features, together with involvement of the nose, larynx, and trachea. There can also be systemic effects, such as convulsions, coma, analgesia, pyrexia, leucocytosis, albuminuria, and pulmonary oedema.

It is uncertain whether the lesions are produced by the action of the whole molecule of dimethyl sulphate or by the products of its hydrolysis, sulphuric acid and methyl alcohol.

In spite of the widespread use of dimethyl sulphate in industry, cases of poisoning are seldom seen. The following cases are reported for this reason and because they showed certain features not previously recorded.

\section{Case Reports}

Case 1.-A. H., aged 20, a male chemistry student, while working in a laboratory on October 28, 1953 , dropped and broke in a fume cupboard a $2 \frac{1}{2}$-litre bottle almost full of dimethyl sulphate and the liquid poured over the edge soaking through his trousers to involve the genitalia and left thigh. His hands were completely covered by the liquid. He immediately washed his hands and treated his trousers with water and $5 / \mathrm{N}$. caustic soda and sodium bicarbonate. Fifteen minutes later he removed the trousers and was washed down with strong ammonia, the trousers receiving similar treatment. There was no tingling or burning sensation in the affected areas though the skin was a little reddened. About one hour after the accident he put on his trousers again and went to a casualty department where a sodium bicarbonate paste was applied to his thighs. He was then feeling perfectly well and, two hours after the accident, attended a lecture. During this he noticed a smell of dimethyl sulphate and a slight soreness of the genitalia.

Three hours after the accident the genitalia were swollen and pink, his eyes were bloodshot, and later his vision became blurred. Four hours after the accident his eyes had become painful, he could not open them, and he was admitted to a hospital casualty ward. He then started to feel ill and was transferred to an eye hospital. Here gross oedema of the lids and extensive excoriation of the corneal epithelium of both eyes was seen. Local treatment with atropine $1 \%$ and liquid paraffin was started but owing to the appearance of severe upper respiratory symptoms he was transferred to this hospital eight hours after the accident.

On admission he was obviously distressed, and was complaining of painful eyes, difficulty in breathing, and retrosternal pain. On examination his pulse rate was $116 / \mathrm{min}$. and his temperature rose to $99 \cdot 2^{\circ} \mathrm{F}$., oedema of the eyelids was extreme and the corneae excoriated. His nose was running, the uvula was swollen, his voice was hoarse and there was marked bronchospasm. Moist sounds could be heard all over the chest.

Treatment was started with atropine, morphine, penicillin, and steam inhalations, and he was placed in an oxygen tent. Thirteen hours after the accident large blisters were noticed on the penis and there were smaller blisters on the scrotum and left thigh. These were covered with sodium bicarbonate compresses.

During his first night in hospital (16 hours after the accident) he coughed up a piece of tissue about 2 in. by 1 in. This was examined microscopically and appeared to be necrotic tracheal mucosa (Fig. 1). The next morning surgical emphysema was felt in the left subclavicular area and it subsequently spread to involve the neck and face (Fig. 2). The patient was able to take fluids by mouth without much distress and it was therefore 


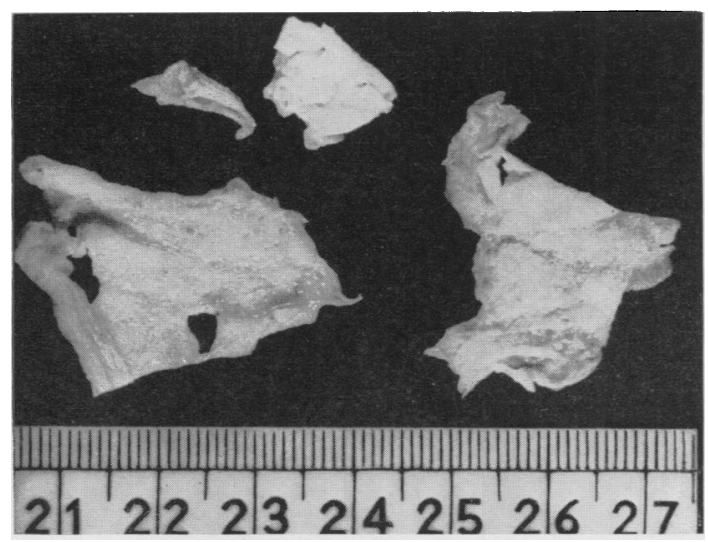

FIG. 1.-Tracheal mucosa expectorated by Case 1. It has been divided into four pieces during pathological examination. (Scale in $\mathbf{c m}$.)

considered that the surgical emphysema was coming from a perforation of the trachea.

On October 29 he was still very ill and distressed by an irritating cough. A blood count revealed a leucocytosis of 25,000 per c.mm. with $90 \%$ polymorphonuclear leucocytes; the haemoglobin was $120 \%$ (Sahli) and the red blood corpuscles numbered 6,090,000 per c.mm. The urine contained a moderate amount of albumin and a few red blood cells.

On October 30 the eye symptoms had lessened and there was no obvious corneal opacity. The bronchospasm had gone but he still had retrosternal pain and was expectorating mucopurulent sputum. The moist sounds had disappeared and the oxygen tent was therefore removed. A radiograph showed normal lung fields and demonstrated the surgical emphysema, which had increased. Serum was pouring from the burnt areas of the penis and scrotum. The oedema of the uvula had subsided and his swallowing was easier.

The condition of his eyes and upper respiratory tract improved steadily during the next week and penicillin

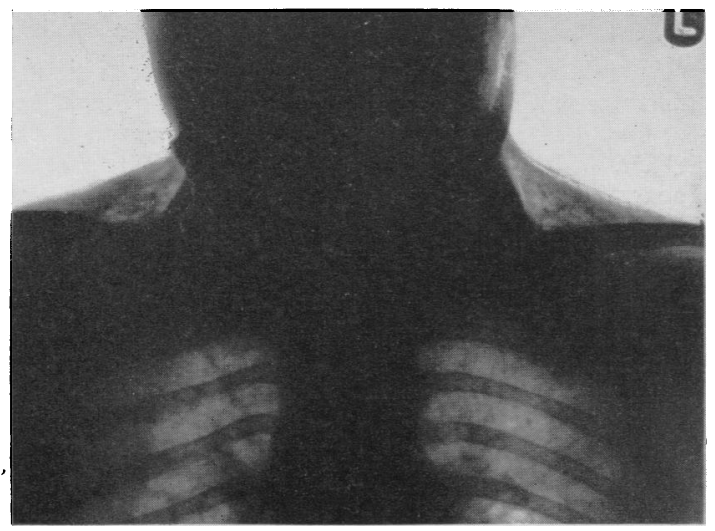

FIG. 2.-Surgical emphysema of neck and face. was then discontinued. On November 6 his eyes showed only slight injection, but there was still photophobia. His voice was still husky but his breathing and cough were much improved, and the surgical emphysema was disappearing. The pyrexia had settled, the albuminuria had disappeared, haemoglobin was $90 \%$, and white blood cells were 10,000 per c.mm. with $84 \%$ polymorphonuclear leucocytes. However, the penile and scrotal burns had become infected; large sloughs eventually separated from the scrotum and the prepuce.

On November 8 there was a recurrence of bronchitis with pyrexia and a course of aureomycin was started. By November 16 he was completely recovered except for the granulating areas on the genitalia, and he was discharged three weeks later.

When seen as an out-patient on January 25, 1954, he appeared well but complained of his eyes aching after reading for a short time. An ophthalmologist could find no abnormality and considered that there was a psychological factor. Laryngoscopy revealed a crescentic scar on the anterior wall of the trachea about $\frac{3}{4}$ in. below the vocal cords, extending about one-third round it but causing no appreciable narrowing of the lumen. This was probably the site of origin of the tissue which he coughed up within 24 hours of the accident.

The genital burns had healed, leaving a stricture of the prepuce which could not be retracted. A circumcision for this was performed on March 31.

Case 2.-D. M., aged 28, was a male process worker employed by a small chemical firm. In November, 1951, he was engaged in the manufacture of an analgesic drug, and in the process dimethyl sulphate was gradually added, as a methylating agent, to a mixture of phenazone and sulphuric acid in a 20-gallon refrigerating pot. This methylating plant was in the open air near the door of the building in which the rest of the process was carried out. On November 21 the patient emptied the refrigerating pot but otherwise did not work with dimethyl sulphate. On November 22 he arrived at work at 8 a.m., changed into the working clothes he had worn the previous day, and then walked past the methylating plant into the building and worked on a process in which dimethyl sulphate was not used. At 10 a.m. he noticed that he had lost the upper half of his visual fields. He was told to breathe ammonia and found he could not smell it. By 11 a.m his upper lids were drooping so much that he could hardly see and he was then taken to an eye hospital. When he arrived there he could not see at all but had no symptoms of discomfort. Five hours later he felt that his penis was swollen though it was not sore, and during the evening his breathing gradually became difficult and he was transferred to the Liverpool Royal Infirmary.

Twelve hours after his first symptoms he had gross swelling of the eyelids, chemosis, excoriation of the corneae, and marked oedema of the soft palate and uvula ; there was bronchospasm, and moist sounds could be heard in all parts of the chest; the penis and scrotum were swollen and vesicated. On admission his temperature was normal and it remained so for 24 hours ; it then rose to $99-100^{\circ} \mathrm{F}$. for two days and was normal 
thereafter. The pulse rate was 50 per minute on admission and during the first 24 hours in hospital it did not rise above 65 per minute ; his normal pulse rate was found to be 75 to 85 per minute after recovery.

Treatment was started with atropine, sulphacetamide, and liquid paraffin drops to the eyes, penicillin intramuscularly, and he was placed in an oxygen tent. By next morning his breathing was easier though the rate was 25 to 30 per minute. The oedema of the fauces slowly subsided and the moist sounds gradually disappeared from the chest. He had to be catheterized for two days after admission. The burns of the penis and scrotum became infected and sloughs later separated.

The eye condition improved gradually and by December 13 only a traumatic conjunctivitis remained, the corneae being clear. However, he still complained of photophobia and this symptom persisted until April, 1952.

He was discharged from hospital on January 4, 1952, the question of circumcision having been raised as the prepuce had become tight and had to be forced over the glans penis. No operation was performed and recovery was complete with no residual diability.

\section{Discussion}

Both cases showed the typical symptoms and signs of poisoning by dimethyl sulphate vapour. How Case 2 became contaminated is uncertain but it is possible that his working clothes were splashed at the end of one day's work and he got burnt after putting them on again next day.

Though both cases were typical, they showed the different modes of presentation which are possible. One man was very distressed with painful eyes and retrosternal pain, whilst the other, almost as badly burnt, had no discomfort for nearly 24 hours. This analgesia has been described in experimental animals by Auer (1918) who found that it may last for as long as six months; he also states that soldiers in the field can undergo surgical procedures without anaesthesia if they have been gassed by dimethyl sulphate (Auer, 1922). It is interesting that Case 2 required no analgesics for one week after admission.

The tachycardia in Case 1 was found in two cases reported by Mohlau (1920). We have not found any reference in the literature to the bradycardia which was a prominent feature in Case 2 during the first 48 hours.

The haemoconcentration and albuminuria which were found in Case 148 hours after admission have been previously described (International Labour Office, 1930). Peripheral neuritis such as described by Cuthy (1940) was not present in either of our cases.
Another feature not previously described in the literature is the surgical emphysema which developed in Case 1. It was presumably due to air leaking through the weakened tracheal wall at the site from which he had lost the mucosa ; probably air only escaped into the tissues during bouts of coughing.

The prognosis in dimethyl sulphate poisoning has been improved during the past 10 years by the use of antibiotics in the control of respiratory tract infections.

In several reports of cases of dimethyl sulphate poisoning (Mohlau, 1920 ; Bodenstein, 1921 ; Strothmann, 1929 ; Merkelbach, 1943 ; von Nida, 1947) we have been unable to find any reference to the use of oxygen in treatment. We believe that the oxygen tent and steam inhalations are most valuable in relieving respiratory distress.

If patients do not die from dimethyl sulphate poisoning, recovery is usually complete, but some symptoms and disability may persist for months. Photophobia, colour blindness, and some loss of visual acuity were reported by Mohlau (1920) to be still present six weeks after poisoning. In Case 1 some aching of the eyes when reading was present three months after admission and in Case 2 the photophobia persisted for four to five months. Extensive scarring of the prepuce may necessitate circumcision, as happened in one of our cases.

\section{Summary}

The physical properties of dimethyl sulphate and its uses are briefly described.

Two cases of poisoning showing the typical clinical picture are reported.

Bradycardia and surgical emphysema affecting the face and upper thorax were features not previously recorded.

The value of antibiotics and oxygen in treatment is stressed.

We wish to thank Dr. E. Wyn Jones for permission to publish Case 2 which was under his care. Our thanks are also due to Dr. H. S. Pemberton, Dr. A. Thelwall Jones, and Dr. A. Lloyd Potter for their advice and help in the preparation of this paper.

\section{REFERENCES}

Auer, J. (1918). Proc. Soc. exp. Biol., N.Y., 15, 104 Auer, (1922). J. exp. Med., 35, 97 .

Bodenstein, J. (1921). Wien. klin. Wschr., 34, 226.

Cuthy, F. (1940). Z. Unfallmed. Berufskr., 34, 34.

International Labour Office (1930). Occupation and Health. Geneva.

Merkelbach, O. (1943). Schweiz. med. Wschr., 73, 481.

Mohlau, F. D. (1920). J. industr. Hyg., 2, 238.

Nida, S. von (1947). Klin. Wschr., 24, 633.

Strothmann, H. (1929). Ibid., 8, 493 . 